\title{
Article
}

\section{Language and science: products and processes of signification in the educational dialogue}

\author{
Martin Dodman, Elena Camino, Giuseppe Barbiero \\ Global changes such as urbanisation, new ways of travelling, new information and communication \\ technologies are causing radical changes in the relationships between human beings and the \\ environment we are both a part of and depend on. Relationships which-according to a multiplicity of \\ researches in various fields - are crucially important. Science education and the language of science risk \\ exacerbating a tendency towards objectifying nature and inhabiting a virtual reality, thereby rendering \\ ever more tenuous the dialogue between people and the natural world. This article examines two \\ approaches to science and language - as products or as processes - and suggests how awareness of the \\ dynamic relationship between language and knowledge can help restore that vital dialogue.
}

\begin{abstract}
To say that cognition is embodied means that it arises from bodily interactions with the world. From this point of view, cognition depends on the kinds of experiences that come from having a body with particular perceptual and motor capacities that are inseparably linked and that together form the matrix within which memory, emotion, language, and all other aspects of life are meshed. [30]
\end{abstract}

As of 2007, for the first time in the history of humanity, more people live in cities than in rural areas [1]. At the same time, new means of communication permit access to an unprecedented quantity and variety of words and images, modifying in ways not yet understood representations and interpretations of reality. What are the implications of this profound transformation of perspectives for the ways in which children and young people perceive and express themselves, think and build a view of the world? And to what extent and how do science teachers take account of this global change in their thinking and practice?

\section{The relational nature of knowledge}

Our direct experience with a real, natural world, in which the complexity of the person (the body which acts, the input perceived, the thoughts progressively elaborated) enters into relationship with the complexity of the context (a meadow, a path alongside a stream, the seashore) has undergone a process of rapid change over the last fifty years. The pattern which connects, the dance of interacting parts [3], a meshwork of interwoven parts [17], has given way to objects that are artefacts, persistent in form (walls, roads, trains), with well-defined contours. The variety of characteristics, novelties, surprises and actions that accompanies the relationships between different forms of life has in part been substituted by a static world, from which it is easy to feel separate. Also ways of travelling have changed. Often it is no longer our bodies that move, describing a trajectory in space, coming to know a territory with eyes, muscles and proprioceptors, but rather means of transport that move us from one node to another within a network, while we remain passive [17].

While a web of threads and traces (the complexity of nature) is being fragmented into nodes and connectors in our physical experience, an analogous fragmentation is taking place at the cognitive level. In fact, one of the most powerful conceptual tools of modern science - the ability to circumscribe times, spaces, problems, and render discrete processes and phenomena in order to analyse and measure them has revealed critical aspects too. The prevailing analytical approach, based on a disciplinary view and an increasing specialization of scientific research, offers a fragmented view of natural systems, that is not sufficiently balanced by an integrative vision: according to some Authors [11] there is a need to assume a holistic approach (looking at wholes rather than merely at their component parts), and an interdisciplinary research style. Looking at the whole from a scientific viewpoint implies investigating 
how different components and processes interact functionally to generate system level responses and emergent properties. Moreover, a holistic, integrative approach accepts and values these interlinkages and interdependences between 'subject' and 'object', between the ways we interpret and give sense to the world and the world itself that gives form to our thoughts.

Many forms of research, developed within diverse disciplinary fields, reveal interesting points of convergence in identifying the essential role of relationships within any attempt to make sense of the world. From many perspectives emerges the idea that no process or phenomenon that concerns human beings (culture, mental categories, language) can be explained without reference to the complex matrix that connects the various parts that come into play. Anthropologists, psychologists, neuroscientists look at individual and collective human characteristics as properties that emerge from complex relationships and are considered much more elaborate than once believed.

Perception and action - that have been traditionally considered separate domains, each of them being implemented in separate anatomical and functional brain sectors - are shown as deeply interconnected: perception requires action [4]. Key aspects of human social cognition, as conscious awareness of actions and spatial location, are generated through the same neurophysiological mechanism for sensory-motor integration [8],[9]. The capacity of these connected functions to "validate" experience renders them unique for acquiring knowledge, perhaps even abstract knowledge about the external world [24],[10].

The experimental results of the neurosciences thus validate the concept of 'embodied cognition' [31] whereby human cognition and consciousness can only be understood in terms of the enactive structures in which they arise, namely the body and the physical world with which the body interacts. This close coupling of the body (with its perceptive, cognitive and motor components) and surrounding world has been placed by Bateson within the frame of the "pattern that connects". "There is relevance, or connectedness between the internal parts of an organism. There is also context, which is the basis for meaning. Temporal context intersects with spatial context and shows the continuity of interaction between creature and environment. And so, the definition of something is based on relation and not on what it pretends to be in itself: all communication necessitates context. [...]. Without context, words and actions have no meaning at all" [3].

Also anthropological studies emphasize the importance of relational aspects. Ellen [7], in a recent review of ethno-biological research, expresses similar ideas to Bateson in arguing that the study of human conceptualization and classification of the natural world is ever more based on the dynamic simultaneous influences of the ecological and social contexts that underlie biological and cultural history (including natural selection, cultural adaptation and social continuity). Cognition of the natural world evolves through interaction with the knowing subject [26].

\section{A transformation in relationships}

As we have already noted, at the same time as this growing awareness of the importance of relationships has developed, a progressive distancing from the natural environment (of which we are however a part), caused by the spread of urbanisation and by the development of energy 'slaves' [5] and technological, exosomatic tools [12] that intervene between us and nature, has led to a loss of direct experience of nature and of spontaneous, unmediated learning that this gives rise to [18],[19].

A significant example concerns modes of travel. "The transported traveller becomes a passenger, who does not himself move but is rather moved from place to place. The sights, sounds and feelings that accost him during the passage have absolutely no bearing on the motion that carries him forth. [...] Thus the very places where the wayfarer pauses for rest are, for the transported passenger, sites of activity. [...]. In between sites he barely skims the surface of the world, leaving no trace of having passed by or even any recollection of the journey" [17].

At the same time, the development of television and computer-based means of communication has given the chance for a multiplicity of virtual circumstances, in which people are placed in decontextualised situations, where emotions, thoughts, interpretations are no longer based on personal and physical experiences, actions and consequences, but rather derive from a passive exposition to "fictitious" facts and images. A natural and real complexity, which includes subjects in a network of 
relationships and interdependencies, is progressively substituted by a virtual one, in which the subject observes from the outside without being directly involved. ${ }^{1}$

Even scientific knowledge - in particular natural sciences, that underwent a vast and rapid spread over the past twenty years - has contributed, albeit involuntarily, to breaking the relationship between sensorimotor experiences gained through acting in the world and the cognitive processes of understanding the world and of constructing concepts. Scientific knowledge has led to the exploration of phenomena and processes ever more distant from our personal perceptive abilities, through the use of instruments (from the microscope to the camera and the elaboration of images) and interpretative processes which are highly abstract. Increasingly we give names to things with which we do not enter into a direct relationship and for which we do not have shared experiences with others. Such moving away from the natural context, from real to virtual, implies that pronouncing a word no longer evokes a personal experience, profound, complex, lived, articulated, which connects the inner self with the world outside in a network of relationships; nor does it allow each of us to collectively share the same meaning with other members of our own community.

How can educational systems take into account these huge and pervasive changes? Are there ways to reconnect people with natural systems, recuperate the intimate bond that couples locomotion, perception and cognition? How can teachers help every young people to inhabit the earth, that is "to participate from within in the very process of the world continual coming into being, $[\ldots]$ and, in laying a trail of life, to contribute to its weave and texture?" [17].

\section{Knowledge and language}

The hypotheses of "embodied cognition" and "the pattern which connects", together with the idea of dynamic simultaneous influences of ecological and social contexts, have important linguistic implications. Anthropologists concerned with ethnobiology emphasize how knowledge of the world is more complex, articulated and multi-channel than words can at times express.

Like any tool, language has its limits. Moreover, these limits risk being the limits of the world we perceive [32]. The limits are manifest in different ways in spoken and written language. One particular example is the way in which "the written word is often inadequate to grasp the precise way in which local peoples perceive their environment [...]. The synaesthetic reality of sensory perception of the environment can be reduced to written texts only with difficulty, and this is partly the reason why it is so hard to reduce practical or embodied ethnobiological knowledge to a written text. Recent cognitive anthropology has now effectively demonstrated the ability of the mind to make sense of much ecological knowledge, and indeed culturally to transmit such data, without constantly converting it into language" [7].

Cognition of the natural world evolves through interaction with the knowing subject. Ecosystem dynamics and human agency intertwine, according to the dialectic of an inalienable link between nature and culture [29]. Such a perspective leads us to enquire to what extent an implicit knowledge of nature is produced by highly urbanised human communities, compared to the ecological knowledge (even if not expressed through natural language) possessed by people who live in direct contact with natural environments.

\section{Science and language as products}

The prevailing approach to science education, which proposes definite and quantified results based on ever more fragmented parts of the world, reinforces the perspective of separation between subject and object. This tends to hide the total dependence of humanity on natural systems, together with the contextual and dynamic character of our thought, ignoring how "we are creatures of context, of time, place and zeitgeist" [23]. Also the language we use often becomes a vehicle of separation and objectification. Developing awareness of the characteristics of language and its role in elaborating and transforming scientific thought can be a significant way of improving the quality of scientific education and reconnecting people with the natural systems on which they depend, with many important consequences.

1 Healey [16] describes a correlation between disturbances such as a deficit of attention and hyperactivity and the hours spent by children in front of a television. The study seems to identify the rapid succession of television images as the principal reason for weakening the attention span and consequent hyperactivity and impulsiveness. 
Language is a way of being in the world, an instrument which enables us to conceive, organise and represent a view of reality and act according to that view. It is a system made of signifiers (words, symbols, images, etc.), interconnected elements that create links to exploit the mind's potential for the construction of signifieds (meanings). This "meaning potential" emerges through our dialogue with the world (both surrounding and within us) and the people with whom we interact via the "social semiotic" of language [13]. Science education often proposes an idea of language as a rigorous and efficient tool whose acquisition is indispensable for understanding scientific questions. "Almost all we customarily call 'knowledge' is language, which means that the key to understanding a subject is to understand its language." [27]. Unfortunately, attention is concentrated on acquiring a specialised language, characterised by a correspondence between signifier and signified as clear and univocal as possible. Moreover, the objective is to develop a language which is nominal, synoptic and abstract [15], considered able to express economically and unambiguously thoughts and notions, a language which is, however, very distant from that which is verbal, dynamic and concrete, typical of everyday experience.

This attitude, widespread at all levels of education from primary school to university, risks furnishing an inadequate, or at least partial, view both of language and science. The choice of consolidated concepts, transmitted via an "appropriate" language, expresses an idea of science as the discovery of reality as it is, a knowledge of the world ever broader and surer, the result of debates or controversies by now resolved. The implications for science education of such an epistemological view are by now amply documented. A number of studies conducted among prospective and practicing science teachers suggest that there is a "tendency to picture scientific knowledge as knowledge of something rather than knowledge which is socially constructed and negotiated" [6]. Moreover, in keeping with this thingifying vision of science "teaching strategies are made use of in which telling and showing predominate, strategies in other words which are generally little prone to grant students' experience-based knowledge any sort of relevance” [6].

\section{Science and language as processes}

In fact, scientific knowledge is in perennial transformation. New experiments and measurements, new methodologies, new contexts continuously modify, enrich, at times replace, previously-held knowledge. "Paradigmatic" changes - as described by Kuhn [20] — are made possible by the production of new ideas, concepts and metaphors that require a constant renewal of language through a redefining of the relationship between signifiers and signifieds, or even the invention of new signifiers. Thus the construction of new scientific knowledge implies the creation of new forms of language and new ways of interpreting the interaction between signifier and the meaning constructed. In this way, paying more attention to language means being aware that there exist different ways of "understanding a subject". Beyond that — most widespread in science education - which identifies, distils and presents consolidated notions, concepts and definitions, using carefully-chosen "unambiguous" words, there is another (typical of research activities) which expresses doubts and uncertainties, also emotions, recognising the dynamic and transitory characteristics of knowledge, inventing new ways of saying, describing or explaining. A reality that is "simultaneously real, like nature, narrated, like discourse, and collective, like society" [25].

This way of doing and talking about science corresponds to a more interactive and dialogic relationship between teacher and student, within a "humanistic perspective" [2] in science education, in which communication becomes vehicle both of the construction of meaning and of the growth of the people involved in that construction. Encouraging students to express themselves and their own ideas not only helps their previous knowledge and misconceptions emerge, but also enables them to exercise their narrative and argumentative skills, together with their ability to co-construct knowledge and themselves at the same time. In other words, it allows them to be active participants in the processes of signification that are the very basis of learning.

In language, signifier and signified define each other reciprocally through our dialogue with the world and its members [14]. Out of this reciprocal relationship comes the sign, the sense that we make of or give to the reality around us and within us. And every signifier continuously redefines itself through its interaction with the signified. All that we construct comes from the system of signs at our disposal, problematising and thereby enriching it with new meanings, which permit the construction of new knowledge, giving rise to new signs. If, however, signifier and signified become permanently "stuck together" in the mind, the result is that word and object are (con)fused, as if they were the same thing, 
with a consequent loss of awareness both of the role of the signifier in the construction of meaning and of the possibility of a plurality of meanings and points of view.

This is what happens in science education when a transmissive approach leads to rote knowledge, to a memorising of labels. Until quite recently the consequences were relatively limited, whereas today the risk is that of exacerbating the worrying tendency towards a generalised loss of sense, of the meaning of things. As we underlined before, we are now faced by a reduction of direct experience of natural systems caused by processes of urbanisation and consequent lack of opportunities to explore and build a personal knowledge of nature. Ever more frequently names are learnt for objects or processes which are not directly encountered. Signifiers are no longer enriched - through real experience - by a multiplicity of signifieds. Urbanisation and the development of global communication systems and virtual worlds have led to the loss of a common natural environment which for thousands of years permitted members of human communities to share a system of signs.

Constructing a sign as part of the process of constructing knowledge requires a plurality of signifieds. If we take away this plurality, there remains only a label. Yet we inevitably eliminate the plurality when we distance the object of our exploration from experience. The processes of signification should lead to signifieds that are dynamic and flexible. A transmissive approach to science education, based on nominal language and emphasizing products rather than processes, risks creating a (con)fusion between signifier and signified and consequent thingifying of nature. ${ }^{2}$ Worse still, our progressive alienation from the natural world, the separation between experience and language, renders highly likely the risk of no longer even producing meanings. If there is no longer reciprocal definition between signifier and signified, then the signifier becomes elevated to the status of empty sign. The processes of signification lead to products without meaning, without sense.

\section{Changing perspectives}

Our signs risk being emptied of sense, our signifiers impoverished and banalised. In the face of an external world without meaning and a total lack of interiorisation of signifieds, what are the consequences for the people who, through the realisation of the meaning potential of language, continually construct themselves? If there is no longer correspondence, or resonance, between external and internal worlds, the inevitable result is the loss of the complexity which can only come from the dialogue between complex systems that gives rise to new signifieds and signs.

In the past the prevailing idea of school was that which emphasized an intelligence expressed through words, considering language as a tool for labelling existing meanings, conventional signs considered objective and constant. This approach to teaching was, however, based on a context still characterised by a direct contact with nature, which permitted a relationship between words and experiences. Now the risk is that of not constructing new signs and rendering meaningless those already existing.

There are many different ways in which science education can promote a change of direction. In themselves, these ways may not be particularly new, but we believe that if they are followed with persistence and informed by awareness of the changes in course within our life contexts, they can enhance the role of science education in enabling individuals and citizens to handle these transformations.

- Recovering the importance of direct experience in natural environments in which motor abilities, sensory perceptions, intuitions and emotions enter into relationship in a variety of constantly changing situations, thereby creating a network of traces left in the memory which can be subsequently recalled [22]. Such experiences can never be replaced by exposure to various forms of multimedial input, an extensive use of which merely proposes signifiers without meaning and denies language its role in constructing concepts.

- Building a dynamic and dialogic communication between teachers and students, with a balanced use of verbal language (based on concrete and dynamic experience) and nominal language (with its abstract and synoptic perspective), narrative mode (the language of doing, of happening, of actions

\footnotetext{
${ }^{2}$ A clear example is the use of the double helix as a metaphor of a molecule of DNA and the subsequent (con)fusion between the concept of gene and a molecular structure. This has encouraged the development of misconceptions still widespread in science degree students training to become teachers. The gene becomes identified with a fragment of DNA, in spite of the fact that the current view in molecular biology recognises that in the protein synthesis of eukaryotes a number of fragments of DNA, various enzymes and types of RNA interact, and proposes a systemic view of structures, processes and functions which contribute to the dynamic and transitory definition of the gene [21].
} 
and intentions) and paradigmatic mode (concepts expressed "systematically" through definitions, explanations, expositions and argumentations), can help students gain meaningful access to the accumulated cultural resources offered by science.

- Using models and metaphors to create awareness of the need for a creative use of language in developing new scientific knowledge. Metaphors are tools for representing and interpreting aspects of the natural world and at the same time reveal the cultural roots and systems of values "embedded in and unselfconsciously conveyed by the apparently impersonal conceptual instruments of analysis" [28]. An incorrect and rigid use of models and metaphors can lead to crystallised concepts, confused signifiers and signifieds and consequent hindering of the development of new ideas and interpretations.

\section{Complexity and plurality}

Awareness of the inextricable interdependence between language, knowledge of the world and knowledge of the self, as well as of the dynamic and continuously negotiated nature of scientific knowledge, ever more mediated by technology, can help change both objectives and approaches to science education. Inclusion in nature - reconnecting with the natural systems on which we entirely depend - can facilitate a reconstruction of the sense which informs the dialogue between ourselves and nature and which derives from the dynamic interaction between signifiers and a plurality of signifieds, thereby restoring the common ground necessary for human beings in order to construct and share signs. An idea of science which promotes a variety of perspectives and which includes students in the processes of signification and knowledge building, can contribute to rendering words more fluid, less "encrusted" or static, giving them back the power to construct new meanings.

Perhaps today a change of paradigm — both in scientific research and education — is already taking place. The confusion between signifier and signified and consequent loss of meaning can be seen as a precursor of a new way of constructing relationships between signifiers and signifieds, concepts and knowledge, a way of recognising the provisional nature of scientific discovery, a way of embracing complexity and being a part of it. We believe that awareness of language has a vital role to play in reuniting signifier and signified in a dynamic relationship.

\section{Acknowledgments}

This research was conducted with the support of the University of Torino and the Piemonte Region, Department of the Environment (PIES 2006/07 - Integrated Programme of Education to Sustainability).

\section{References}

[1] AA. VV., State of the World 2007 - An urban planet, Worldwatch Institute, Washington (2007).

[2] G. Aikenhead, Science education for everyday life, New York, Teachers College Press (2006).

[3] G. Bateson, Mind and Nature: A Necessary Unity, Bantam Books (1979).

[4] A. Clark, Being There: Putting Brain Body and World Together Again, Cambridge, MA, MIT Press (1997).

[5] K. Cobb, The energy slaves, Le monde diplomatique, May 2006.

[6] J. Désautels and M. Larochelle, About the epistemological posture of science teachers, in Connecting Research in Physics Education with Teacher Education, A. Tiberghien, E.L. Jossem and J. Barojas (eds), I.C.P.E. Book (1998).

Available at $<$ http://physics.ohio-state.edu/ jossen/ICPE/D3.html $>$.

[7] R.F. Ellen, Introduction Ethnobiology and the Science of Humankind, Journal of the Royal Anthropological Institute 12 (2006) S1.

[8] V. Gallese, The "Conscious" Dorsal Stream: Embodied Simulation and its Role in Space and Action Conscious Awareness, PSYCHE 13/1, April 2007. 
[9] V. Gallese, Mirror neurons and the social nature of language: The neural exploitation hypothesis Social neuroscience, in press, 2008.

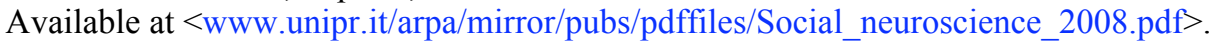

[10] V. Gallese and G. Lakoff, The Brain's Concepts: The Role of the Sensory-Motor System in Reason and Language, Cognitive Neuropsychology 22 (2005) 455.

[11] G. Gallopin, Sustainable development: epistemological challenges to science and technology, paper prepared for the Workshop on "Sustainable Development: Epistemological Challenges to Science and Technology", ECLAC, Santiago de Chile, 13 - 15 October 2004.

[12] M. Giampietro, K. Mayumi and J. Martinez-Alier, Introduction to the Special Issues on Societal Metabolism: Blending New Insights from Complex System Thinking with Old Insights from Biophysical Analyses of the Economic Process, Population and Environment: A Journal of Interdisciplinary Studies 22(2), November 2000.

[13] M.A.K. Halliday, Language as Social Semiotic: The Social Interpretation of Language and Meaning, London, Edward Arnold (1978).

[14] M.A.K. Halliday, Language and the order of nature, in The linguistics of writing: Arguments between language and literature, N. Fabb et al (eds), Manchester, Manchester University Press, (1987).

[15] M.A.K. Halliday, Spoken and written language, Oxford, Oxford University Press (1989).

[16] J.M. Healey, Early Television Exposure and Subsequent Attention Problems in Children, Pediatrics 113 (2004) 917.

[17] T. Ingold, Up, across and along, Place and Location: Studies in Environmental Aesthetics and Semiotics 5 (2006) 21.

[18] P.H. Kahn, The human relationship with Nature, Cambridge MA, MIT Press (1999).

[19] P.H. Kahn and S.R. Kellert, Children and Nature, Cambridge MA, MIT Press (2002).

[20] T.S. Kuhn, The Structure of Scientific Revolutions, Chicago, Chicago University Press (1962).

[21] E. Keller Fox, The century of the gene, Harvard, Harvard University Press (2001).

[22] S.R. Kellert, Kinship to Mastery, New York, Island Press (1997).

[23] D. Knight, Kinds of mind, Nature 447 (2007) 149.

[24] G. Lakoff and M. Johnson, Philosophy In the Flesh: The Embodied Mind And Its Challenge To Western Thought, New York, NY, Basic Books (1999).

[25] B. Latour, Reassembling the Social: An Introduction to Actor-Network-Theory, Oxford, Oxford University Press (2005).

[26] M. Mithen, The prehistory of the mind: a search for the origins of art, religion and science, London, Thames \& Hudson (1996).

[27] N. Postman and C. Weingartner, quoted by J. Wellington, J. Osborne, Language and literacy in science education, Buckingam, OPEN University Press (1971).

[28] J. Ravetz, Models as metaphors. A new look at science, WP-99-3 (1999).

Available at $<$ http://www.zit.tu-darmstadt.de/ulysses/docmain.htm>.

[29] L. Rival (ed.), The social life of trees, Oxford, Berg (1998).

[30] E. Thelen, G. Schoner, C. Scheier and L.B. Smith, The dynamics of embodiment: A field theory of infant perseverative reaching, Behavioral and Brain Sciences 24 (2001) 1.

[31] F. Varela, E. Thompson, E. Rosch, The Embodied Mind, Cambridge, MA, MIT Press (1991).

[32] L. Wittgenstein, Tractatus Logico-Philosphicus, London, Routledge \& Kegan Paul (1974).

\section{Authors}

Martin Dodman, IRIS (Interuniversity Research Institute on Sustainability: www.iris.unito.it ), University of Torino, Dept Animal and Human Biology, Via Accademia Albertina, 1310123 Torino.

A professor of Comparative Education and Didactics of Languages at the Faculty of Education Sciences, Libera Università di Bolzano. A professor of Didactics, languages, science at the SIS (Advanced School for Higher Education) of Turin and of Didactics of Languages at the SIS of Pavia. A member of IRIS. A consultant for educational projects of the Ministry of Public Education and of local institutions regulating the education system on the organisation of schooling systems, the management of innovation in curricula, schooling continuity, educational research, linguistic education and multilingualism.

E-mail: martindodman@libero.it. 
Elena Camino, IRIS (Interuniversity Research Institute on Sustainability), University of Torino, Dept Animal and Human Biology, Via Accademia Albertina, 1310123 Torino, Italy.

A researcher in Didactics of Natural Sciences, a lecturer at the Faculty of Sciences of the University of Torino and at the SIS (Scuola di Specializzazione all'insegnamento Secondario - Advanced School for Higher Education). A founding member of IRIS. She deals with the debate and the didactic experimentation on the non-violent changes in complex and controversial social and environmental issues and on the education to sustainability. E-mail: elena.camino@unito.it.

Giuseppe Barbiero, IRIS (Interuniversity Research Institute on Sustainability), Università della Valle d'Aosta, Via Cappuccini, Aosta, Italy.

A biologist, a doctor in Experimental and Molecular Pathology, a university researcher in Ecology (SSD $\mathrm{BIO} / 07$ ) and a lecturer of Ecology and Biogeosciences at the University of Valle d'Aosta. Since 1999, he is a member of the Group of Research on Didactics of Natural Sciences, at the University of Torino. A founding member of IRIS - Interuniversity Research Institute on Sustainability. Since 2006, he is a coordinator of the Natural Science curriculum (59/A) of the Scuola di Specializzazione all'Insegnamento Secondario (Advanced School for Higher Education - SSIS). E-mail: g.barbiero@univda.it. 